Revue d'histoire de l'Amérique française

REVUE D.HISTOIRE DE L'AMÉRIQUE FRANÇAISE

\title{
COOK, Sharon Anne, Lorna R. McLEAN et Kate O'ROURKE, Framing Our Past. Canadian Women's History in the Twentieth Century (Montréal, McGill-Queen's University Press, 2001), 495 p.
}

\section{Amélie Bourbeau}

Volume 55, numéro 4, printemps 2002

URI : https://id.erudit.org/iderudit/010452ar

DOI : https://doi.org/10.7202/010452ar

Aller au sommaire du numéro

Éditeur(s)

Institut d'histoire de l'Amérique française

ISSN

0035-2357 (imprimé)

1492-1383 (numérique)

Découvrir la revue

Citer ce compte rendu

Bourbeau, A. (2002). Compte rendu de [COOK, Sharon Anne, Lorna R. McLEAN et Kate O'ROURKE, Framing Our Past. Canadian Women's History in the Twentieth Century (Montréal, McGill-Queen's University Press, 2001), 495 p.] Revue d'histoire de l'Amérique française, 55(4), 628-628.

https://doi.org/10.7202/010452ar d'utilisation que vous pouvez consulter en ligne. 
COOK, Sharon Anne, Lorna R. McLEAN et Kate O'ROURKE, Framing Our Past. Canadian Women's History in the Twentieth Century (Montréal, McGill-Queen's University Press, 200I), $495 \mathrm{p}$.

Quatre-vingt-quatre femmes et trois hommes ont collaboré à la rédaction de cet ouvrage, véritable mosaïque de destins de femmes canadiennes du $\mathrm{xx}^{\mathrm{e}}$ siècle. Abondamment illustré et composé de courts articles (deux à cinq pages), Framing Our Past est une lecture aisée pour qui cherche des informations sur des sujets aussi variés que la pratique du 5 o'clock tea au début du siècle ou le travail des femmes à la Scotiabank. Le recueil se veut une synthèse d'histoire populaire des femmes, ce qui a amené les directrices à recruter des collaborateurs de tous les horizons : l'histoire, l'archivistique, les sciences pures, la littérature, l'éducation, la muséologie, le droit, etc. L'éclectisme des genres aurait pu donner un résultat malheureux, mais la vaste majorité des auteurs ont choisi de traiter d'une thématique à partir d'une femme particulière; les mini-biographies ont ensuite été regroupées sous six thématiques différentes, soit la vie quotidienne, la vie de famille, l'enseignement et la fréquentation scolaire, l'activisme politique, la santé et la science et, enfin, le travail. Comme le précise Alison Prentice en avant-propos, un livre d'histoire des femmes destiné au grand public manquait au Canada. L'approche qui a été choisie, combinant histoire populaire, histoire régionale et histoire académique, saura en satisfaire plusieurs. De plus, l'ensemble des articles réussit à couvrir la presque totalité du Canada, exception faite du Québec, presque absent. Il est tout de même rare qu'un ouvrage de synthèse canadien tienne réellement compte des Provinces maritimes, des Prairies et même des Territoires. Cette particularité ne fait qu'ajouter à l'aspect pédagogique de l'œuvre.

AMÉLIE BOURBEAU Département d'histoire Université de Montréal

LITTLE, J. I., dir., Love Strong as Death. Lucy Peel's Canadian Journal, 1833-1836 (Waterloo, Wilfrid Laurier University Press, coll. «Studies in Childhood and Family in Canada », 200 I), 229 p.

Cette édition du journal canadien de Lucy Peel — rendue disponible à un plus large auditoire par J. I. Little - constitue la reproduction (en trois volumes) de la transcription, effectuée par ses descendants, des 33 lettres qu'elle rédigea sous forme de journal intime lors de son séjour au Canada. 